\title{
LA CUESTIÓN FISCAL Y LA FORMACIÓN DEL ESTADO DE COSTA RICA, 1821-1850. PABLO RODRÍGUEZ SOLANO. SAN JOSÉ, COSTA RICA: EUCR. 2017
}

Eduardo Madrigal Muñoz

Sin lugar a dudas, el recién publicado libro del historiador Pablo Rodríguez Solano es una obra fundamental para la historiografía costarricense. La investigación fue realizada como tesis doctoral, en el contexto del programa de investigación "Statebuilding in Latin America", dirigido por el extinto investigador argentino de origen colombiano Juan Carlos Garavaglia, programa que tuvo el apoyo de un Advanced Grant del European Research Council, con sede en la Universidad Pompeu Fabra, en Barcelona. Se tiene, entonces, una versión retomada de la tesis del doctor Rodríguez, ahora convertida en libro.

Como lo indica su título, la obra siempre trasciende el análisis específico de la hacienda pública, para abarcar el ámbito mayor del Estado en su conjunto, por lo que, no solo estudia la hacienda pública, sino todo el marco jurídico e ideológico en que se fundó el Estado y su proceso de creación. El trabajo está organizado cronológicamente y dividido según décadas, cada una de estas se va desmenuzando cuidadosa y profundamente.

$\mathrm{Al}$ igual que otros trabajos recientes de investigadores jóvenes de la misma generación (gente que actualmente transita en la mitad -muchos en la segunda mitad- de sus treintas), el trabajo de Rodríguez tiene un mérito señero. Se ha discutido, en diferentes foros académicos, que este grupo de investigadores -el cual se encuentra en pleno crecimiento como tales- está revisitando seriamente el siglo XIX -ya muy tratado por los historiadores y otros estudiosos liberales y socialdemócratas- de una manera que sacude las certezas establecidas por generaciones anteriores.

Los primeros dos capítulos del trabajo se dirigen a estudiar los orígenes de la temática en las elaboraciones políticas y hacendarias durante el periodo colonial tardío y en el de la Independencia. Desde estos primeros capítulos, la obra propone revisar la teoría que se ha utilizado hasta ahora y replantear el Estado, no solo como concepto, sino también en lo que de este se sabe por la investigación empírica, en particular, por la forma en que se analiza el proceso de construcción de las entidades estatales 
modernas, pero sin dejar de señalar las características coloniales que se mantuvieron por mucho tiempo y que fueron, poco a poco, suplantadas por la modernidad política.

Por lo tanto, el enfoque de Rodríguez hace resaltar que esta modernidad no se impuso de golpe ni fue el resultado de un proceso teleológico, sino que convivió mucho tiempo con factores heredados del pasado, por lo que, el origen del Estado moderno, después de la Independencia, reside en el encuentro entre la tradición y el cambio: continuidades coloniales con modernización en heteróclita fusión que no llegó de la Colonia a la nación de la noche a la mañana. Por ejemplo, uno de los aspectos que destacan en todo el trabajo es que los protagonistas de la época actúan dentro de un marco de costumbres -a la larga más que de ideas- de origen claramente colonial.

Destacable es también el mérito de la obra - presente en el capítulo tercero, aunque en realidad es tema transversal- de empalmar los dos lados de la frontera ideológica y epistemológica establecida artificialmente -más en la mente que en la realidadpor el año 1821. Bien lo dice el autor en el Capítulo 1 de su obra: el año de 1821 es solo una línea imaginaria que inicia una transformación, ya empezada mucho tiempo atrás (¿reformas borbónicas? ¿Cortes de Cádiz?), hacia una modernización política, pero que carga todo un trasfondo colonial.

Resulta básico, como otro aspecto a destacar sobre los primeros capítulos de la obra, que siempre existe una perspectiva signada por el estudio del vocabulario político a lo largo de todo el trabajo. Es impresionante el análisis realizado con esta visión acerca del periodo tardío-colonial e independentista, pero se puede decir lo mismo de todo el resto del libro. Se pone con ello de relieve la introducción en la época de nuevos conceptos y vocabularios emanados de sistemas ideológico-filosóficos presentes en el contexto colonial hispanoamericano, lo cual trastoca severamente las estructuras políticas. Ejemplo de esto son los conceptos de "soberanía", "representación", "pactismo", "cuerpo político", "gobierno", "república", "policía", por mencionar solo algunos de los conceptos utilizados en la época.

Por su parte, un dato interesante -y controversial- de los primeros tres capítulos del trabajo de Rodríguez es que en estos habla de un "pacto" existente entre las elites del Valle Central al momento de la Independencia, el cual permitió la continuidad de su poder y la construcción de un régimen de gobierno interno luego de la emancipación.

Además, sobre la misma línea de este "pacto social" colonial, otro tema destacable por polémico en el trabajo es que reproduce y refuerza la vieja tesis de que la colonización agraria del siglo XVIII, marcada por el mestizaje, generó la democracia costarricense, al propiciar la formación de una sociedad relativamente igualitaria, sin abismos insalvables entre dominadores y dominados.

Por demás, vale la pena hacer notar también que, en los primeros capítulos del trabajo, particularmente en el relativo al periodo colonial, el autor aborda el tema de la hacienda y el Estado con una perspectiva macroimperial; se observa el problema no solo desde la localidad (como han hecho la mayoría de los historiadores hasta ahora), 
sino también desde el punto de vista de la España imperial, desde la península que ve su imperio de ultramar.

En relación con los años posteriores a la independencia y el proceso de arranque de la construcción del Estado que siguió -en particular de la coyuntura crítica de 1823-, el autor hace ver otro hecho muy importante: la reivindicación de la autonomía -que no Independencia- de las colonias, la cual se remonta al siglo XVIII y recuerda el caso de las colonias del Caribe. Esta reivindicación -muy distinta a un ansia de independencia como tal- es producto del surgimiento de un sentimiento de identidad que suele aparecer en las colonias frente a la metrópoli, a medida que aquellas evolucionan y se van distanciando en sus imaginarios de la madre patria que las colonizó. Este sentimiento termina con frecuencia - pero no siempre ni necesariamente- por la independencia, cuando la madre patria y su dominio llegan a un punto de agotamiento.

De aquí en adelante, el trabajo se enrumba hacia lo profundo del proceso de construcción del Estado -tortuoso y con infinidad de retrocesos y callejones sin salida-, por lo que no puede ser visto como un proceso lineal y teleológico-. A este respecto, impresiona la reconstrucción y análisis minucioso que hace del aparato de Estado y hacienda pública durante el periodo federal. De acuerdo con la descripción de Pablo, profunda en análisis, este parece, por cierto, un Estado colonial gaditano, pero en pequeño.

Por demás, el desafío de reconstruir las instituciones recaudadoras y las cifras hacendarias en el caos de la inestabilidad política típica de este periodo de transición es hercúleo, pero el autor de marras lo vence titánicamente, como lo atestiguan las tablas estadísticas que, sobre el tema, ofrece en numerosas páginas de esta sección y en las sucesivas. El trabajo de reconstruir las cifras de la época resulta tremendamente complejo con cuentas tan desordenadas e imprecisas de las cajas estatales (como las que existen para esta época).

Además, se nota, a lo largo de esta sección del trabajo, la continuidad colonial en una plétora de elementos, por ejemplo, en cuanto al tipo de impuestos que se cobraban (tal es el caso de la alcabala), así como también en la legislación utilizada en la época. Por ejemplo, viejas leyes heredadas del coloniaje siguieron vigentes por buen tiempo, como fue el caso de la Constitución de Cádiz, o bien la Ordenanza General de Intendentes de la Nueva España, que rigió en Costa Rica hasta 1839. La continuidad con el periodo colonial también es visible en relación con la multiplicidad de cajas recaudadoras independientes que existían aparte de la del Estado naciente, rasgo muy propio de la multiplicidad colonial de poderes.

Como reflexión lateral sobre los temas planteados por el autor, cabe decir que no deja de llamar la atención el hecho de que el tema del déficit de las finanzas públicas y del pago a los funcionarios estatales era problemático en aquel entonces, y lo sigue siendo actualmente. Por ello claramente este libro les va a interesar -o por lo menos les debería interesar- muchísimo a los políticos y tecnócratas públicos de hoy. 
Problemas como el gigantismo e improductividad de la planilla estatal y el salario público como componente inflexible del gasto, así como el problema recurrente de déficit en las finanzas estatales, se discutieron en las décadas de 1840 y 1850 también. Asimismo, se discutieron temas que aún hoy siguen siendo candentes, como la deuda pública y la construcción de infraestructura.

Resulta fundamental también la forma en que Rodríguez acomete el tema de la aparición del funcionariado público con las reformas de Carrillo desde 1839 (lo cual, por cierto, empata con lo que está investigando el autor actualmente, natural continuación sabiamente elegida). Este funcionariado moderno en ciernes ya empezará a estar dotado, como lo analiza en los trabajos que se encuentra realizando, de una ética de servicio público impersonal, en contraste con el espíritu de "servicio al rey" del periodo colonial. Lo anterior representa verdaderamente la transición de la Colonia al Estado moderno.

En los capítulos 5, 6 y 7 se estudia cómo el Estado extiende su control a todas las instituciones políticas, con lo cual pone fin al poder omnímodo de los municipios -indudable herencia colonial-y logra una mayor centralización, a partir de la década de 1840. La descripción minuciosa de la manera en que funcionan y se construyen, una a una, todas las instituciones del Estado en esta década es admirable.

De nuevo, múltiples son las continuidades coloniales que el autor pone de relieve para este periodo, mano a mano con la aparición de un régimen nuevo. Una de estas es que, aún en la década de 1840, el ministerio de Hacienda concentraba también al de Guerra y Marina, a la usanza borbónica, que fusionaba las dos cosas por considerarlas estrechamente ligadas. También menciona que -al igual que en la Colonia- los ramos estancados y monopolios de la hacienda nacional (uno de los cuales permanece vivo hasta ahora) eran la principal fuente de ingresos del Estado naciente.

Aún la Sociedad Económica Itineraria -potente en esta época- tuvo carácter de corporación colonial, primero porque ya durante el periodo del reformismo borbónico se habían creado muchas sociedades de este tipo en la Hispanoamérica de la Colonia tardía y, segundo, porque, aun bien entrado el siglo XIX, el carácter y función de esta institución no se alteró significativamente. Por demás, el hecho de que cada ramo de la hacienda estatal tuviera su propio régimen de justicia es también un rasgo colonial, típico del Antiguo Régimen. En Costa Rica se nota, por ejemplo, que, a la usanza de la multiplicidad colonial de poderes, la hacienda estatal de Costa Rica pagaba su propio cuerpo de resguardos.

Son también rasgos coloniales vigentes en esta época que los funcionarios públicos fueran pagados de los mismos impuestos que recaudaban, que los remates de estanquillos y tercenas fueran a nutrir ganancias privadas y que hubiese cobros diferenciados para los hijos de familias consideradas de abolengo en la época, en relación con las contribuciones estatales para infraestructura. No faltan tampoco para este periodo los cuadros detallados de los ingresos y gastos públicos, una titánica reconstrucción. 
Es una lástima, sin embargo, al respecto de estas últimas décadas analizadas, que el trabajo no desarrolle ampliamente el tema del modelo napoleónico de administración -que se aplica a la burocracia que nace-. Esto sin duda le hubiera dado una muy buena dimensión comparativa al trabajo y mayor visión global; no cabe duda de que este es un tema sobre el que Rodríguez reflexionará en trabajos que tiene en curso.

Finalmente, resalta, de manera perturbadora para los discursos establecidos, la brillante explicación sobre el triunfo en la Campaña Nacional como resultado de la acción de una comunidad de intereses que estaba interesada en sostener un Estado estable, con finanzas sólidas, para apuntalar sus empresas comerciales y cafetaleras.

En resumen, es de gran valor el seguimiento que se realiza en la obra del proceso de estructuración institucional del Estado costarricense en ciernes, el cual no pierde de vista en ningún momento la pervivencia de las viejas características políticas coloniales, en lenta suplantación por parte de la modernidad política.

Para concluir, al tener en las manos esta obra transgresora, sugerente y por demás estimulante, no se puede evitar caer en conciencia de que su autor definitivamente es alguien que sabe escribir historia. Su erudición y agudeza a la hora de analizar su periodo de estudio es verdaderamente brillante.

No obstante, más que cualquier otro asunto que se pueda decir, queda claro que obras como la de Rodríguez arrojan luz sobre temas que son injustificablemente desconocidos. Con este y otros textos que se conocen, o bien se conocerán, es posible descubrir información acerca del costarricense como sociedad, lo cual conlleva a entenderlo cada vez mejor.

Eduardo Madrigal Muñoz. Costarricense, doctor en Historia por la Universidad de Costa Rica y la Universidad de Toulouse II-Jean Jaurès, Francia. Profesor de las escuelas de Historia y Estudios Generales de la Universidad de Costa Rica; profesor invitado en la Universidad de Toulouse II-Jean Jaurès de enero a febrero de 2015; investigador del Centro de Investigación en Identidad y Cultura Latinoamericana (CIICLA), Universidad de Costa Rica.

Contacto: edmadm@yahoo.es

ORCID: 0000-0003-1347-9922 
